\title{
Effect of mixing structure on the water uptake of mixtures of ammonium sulfate and phthalic acid particles
}

\author{
Weigang Wang ${ }^{1,4} \star$, Ting Lei ${ }^{2,3} \star$, Andreas Zuend ${ }^{5}$, Hang $\mathrm{Su}^{3}$, Yafang Cheng ${ }^{2}$, Yajun Shi ${ }^{1}$, Maofa Ge ${ }^{1,4,6}$, and \\ Mingyuan Liu ${ }^{1,4}$ \\ ${ }^{1}$ State Key Laboratory for Structural Chemistry of Unstable and Stable Species, CAS Research/Education Center for \\ Excellence in Molecular Sciences, Institute of Chemistry, Chinese Academy of Sciences, Beijing 100190, PR China \\ ${ }^{2}$ Minerva Research Group, Max Planck Institute for Chemistry, Mainz 55128, Germany \\ ${ }^{3}$ Multiphase Chemistry Department, Max Planck Institute for Chemistry, Mainz 55128, Germany \\ ${ }^{4}$ University of Chinese Academy of Sciences, Beijing 100049, PR China \\ ${ }^{5}$ Department of Atmospheric and Oceanic Sciences, McGill University, Montréal, Quebec, Canada \\ ${ }^{6}$ Center for Excellence in Regional Atmospheric Environment, Institute of Urban Environment, \\ Chinese Academy of Sciences, Xiamen 361021, PR China \\ « These authors contributed equally to this work.
}

Correspondence: Weigang Wang (wangwg@iccas.ac.cn) and Maofa Ge (gemaofa@iccas.ac.cn)

Received: 24 June 2020 - Discussion started: 28 July 2020

Revised: 4 November 2020 - Accepted: 14 December 2020 - Published: 15 February 2021

\begin{abstract}
Aerosol mixing state regulates the interactions between water molecules and particles and thus controls aerosol activation and hygroscopic growth, which thereby influences visibility degradation, cloud formation, and its radiative forcing. There are, however, few current studies on the mixing structure effects on aerosol hygroscopicity. Here, we investigated the hygroscopicity of ammonium sulfate/phthalic acid (AS/PA) aerosol particles with different mass fractions of PA in different mixing states in terms of initial particle generation. Firstly, the effect of PA coatings on the hygroscopic behavior of the core-shell-generated mixtures of AS with PA was studied using a coating hygroscopicity tandem differential mobility analyzer (coating HTDMA). The slow increase in the hygroscopic growth factor of core-shell-generated particles is observed with increasing thickness of the coating PA prior to the deliquescence relative humidity (DRH) of AS. At relative humidity (RH) above $80 \%$, a decrease in the hygroscopic growth factor of particles occurs as the thickness of the PA shell increases, which indicates that the increase of PA mass fractions leads to a reduction of the overall core-shell-generated particle hygroscopicity. In addition, the use of the Zdanovskii-StokesRobinson (ZSR) relation leads to the underestimation of the measured growth factors of core-shell-generated particles
\end{abstract}

without consideration of the morphological effect of coreshell-generated particles, especially at higher RH. Secondly, in the case of the AS/PA initially well-mixed particles, a shift of the DRH of AS $(\sim 80 \%$, Tang and Munkelwitz, 1994) to lower RH is observed due to the presence of PA in the initially well-mixed particles. The predicted hygroscopic growth factor using the ZSR relation is consistent with the measured hygroscopic growth factor of the initially wellmixed particles. Moreover, we compared and discussed the influence of mixing states on the water uptake of AS / PA aerosol particles. It is found that the hygroscopic growth factor of the core-shell-generated particles is slightly higher than that of the initially well-mixed particles with the same mass fractions of PA at RH above $80 \%$. The observation of AS / PA particles may contribute to a growing field of knowledge regarding the influence of coating properties and mixing structure on water uptake.

\section{Introduction}

The ability of aerosol particles to absorb and maintain water molecules, called hygroscopicity, is one of the most important physicochemical properties of atmospheric aerosol par- 
ticles with profound implications (Shi et al., 2012; Lei et al., 2014, 2018; Gupta et al., 2015; Hodas et al., 2015; Zawadowicz et al., 2015; Martin et al., 2017). It might determine the phase state (Mu et al., 2018), size (Peng et al., 2001; Choi et al., 2002), mixing state, optical properties, and chemical reactivity of atmospheric aerosols exposed to the environment of different relative humidities (RHs) (Heintzenberg et al., 2001; Rudich et al., 2003; Spindler et al., 2007; Abo Riziq et al., 2007, 2008; Eichler et al., 2008). Moreover, changes in these properties after water absorption on aerosol particles can strongly affect cloud formation, aerosol radiative forcing, global climate, and even human health (Cheng et al., 2008; Reutter et al., 2009; Rose et al., 2011; Stock et al., 2011; Liu et al., 2012, 2013; Tie et al., 2017). Therefore, the interaction between water molecules and aerosol particles is crucial for a better understanding of aerosol-cloud-climate effects in the atmosphere (Sjogren et al., 2007; Zamora et al., 2011; Jing et al., 2016).

Atmospheric aerosols contain a complex mixture of inorganic and organic compounds in different mixing structures, e.g., externally mixed or internally mixed (Ganguly et al., 2006). The internally well-mixed aerosol particles may be divided into homogeneous and heterogeneous internally mixed aerosol particles (Lang-Yona et al., 2010), which could, in turn, strongly influence the water uptake, optical properties, and cloud condensation nuclei (CCN) ability of the particles (Lesins et al., 2002; Falkovich et al., 2004; Zhang et al., 2005; Schwarz et al., 2006; Su et al., 2010). Most of the previous studies on the hygroscopic behavior of multicomponent aerosols focus on the well-mixed particles generated from internally mixed solutions (Miñambres et al., 2010; Shi et al., 2012; Gupta et al., 2015; Jing et al., 2016; Lei et al., 2014, 2018). For example, Choi and Chan (2002) studied the effects of glycerol, succinic acid, malonic acid, citric acid, and glutaric acid on the hygroscopic properties of sodium chloride and ammonium sulfate (AS) in the initially well-mixed aerosol particles using an electrodynamic balance. They observed that the deliquescence and efflorescence of sodium chloride and AS were affected by the presence of different organic components in the mixed aerosol particles. Concerning the hygroscopicity of the heterogeneity of internally mixed aerosol particles, such as core-shell particles, there are several studies on their interaction with water molecules (Ciobanu et al., 2009; Song et al., 2012a, b, 2018; Shiraiwa et al., 2013; Hodas et al., 2015). However, to date, few laboratory studies have been reported on the influence of organic coatings on the hygroscopic behavior of core-shell particles and the different mixing state effects on the hygroscopicity of aerosol particles (Zhang et al., 2008; Pagels et al., 2009; Xue et al., 2009; Lang-Yona et al., 2010; Ditas et al., 2018). For example, the hygroscopicity tandem differential mobility analyzer (HTDMA) study on the organic coating effects on the hygroscopicity of core-shell aerosol particles was studied by Maskey et al. (2014). They observed a shift of the deliquescence relative humidity (DRH) of AS to lower RH for the core-shell particles due to the presence of levoglucosan coatings. They further compared water absorption on AS/ levoglucosan core-shell particles and the AS / succinic acid core-shell particles. They suggested that different organic coatings led to changes in the hygroscopic properties of core-shell particles. Chan et al. (2006) investigated the hygroscopicity of AS coated with different mass fractions of glutaric acid during two continuous humidification and dehumidification cycles using a Raman spectrum and an electrodynamic balance. They observed different hygroscopic behavior and morphology of aerosol particles between the two humidification and dehumidification cycles due to the different mixing states. Therefore, investigating the organic coating effect on the hygroscopicity of aerosol particles and further studying the different mixing state effects on the hygroscopic behavior of aerosol particles are crucial for estimating the direct and indirect radiative effect of aerosol particles on the Earth's climate (Saxena et al., 1995; Ansari et al., 2000; Maskey et al., 2014).

Phthalic acid (PA) is ubiquitous in rural mountains and marine atmospheres in Asia (Wang et al., 2011). It is mainly produced by the photo-oxidation of volatile organic compounds (VOCs), such as xylene and naphthalene (Kawamura and Ikushima, 1993; Schauer et al., 1996; Zhang et al., 2016). Also, PA has been identified as a significant contributor to urban organic compounds (Rogge et al., 1993). PA particles are generally used as a tracer for the secondary organic aerosol (SOA) in atmospheric fine particles (Schauer et al., 2000, 2002). Furthermore, aromatic acids like PA, which are photo-oxidation products of anthropogenic precursors such as toluene, xylene, and naphthalene, are initially formed as gaseous products and subsequently condensed onto pre-existing particles. Also, Kleindienst et al. (1999) investigated that hygroscopic particles formed after irradiating toluene, $p$-xylene, and 1,3,5-trimethylbenzene in the presence of $\mathrm{NO}_{x}$ and AS seed in a chamber. This suggests the likely existence of PA in atmospheric aerosol particles. Organic coatings on inorganic aerosol particles in the atmosphere can play an important role in the range of RHs over which particle-bound water influences aerosol properties, such as the overall density, light scattering behavior, and refractive index. Recently, Zhang et al. (2016) reported the importance of atmospheric PA aerosol particles in visibility degradation and the formation of CCN. The organic PA can have a profound effect on light scattering, hygroscopicity, and phase transition properties of multicomponent atmospheric aerosols. However, these physicochemical properties of PA have been sparsely documented in the literature (Brooks et al., 2004; Liu et al., 2016). Here, we summarize a few studies on the hygroscopicity of the PA-containing aerosol particles. Brooks et al. (2004) investigated the continuous hygroscopic growth of PA aerosol particles in the humidification process using the HTDMA technique. Hori et al. (2003) and Huff Hartz et al. (2006) measured the high $\mathrm{CCN}$ activity of PA in spite of its low solubility. Also, liquid- 
liquid phase separation (LLPS) of aerosol particles consisting of organic and inorganic components has been observed by many groups (Ciobanu et al., 2009; Betram et al., 2011; Song et al. 2012a, b; You et al., 2014). For example, Song et al. (2012a, b) reported that LLPS occurs in the mixed dicarboxylic acids containing 5, 6, and 7 carbons using optical microscopy and micro-Raman spectroscopy and further established that the occurrence of LLPS of aerosol particles has an average elemental oxygen-to-carbon $(\mathrm{O}: \mathrm{C})$ ratio of the organic fraction of less than 0.8 . Subsequently, the occurrence of LLPS in the internally mixed aerosols consisting of AS and PA was performed by Zhou et al. (2014) during the dehumidification processes using a Raman spectrum. You et al. (2014) further found that the LLPS of aerosol particles with a different $\mathrm{O}: \mathrm{C}$ ratio of $0.5<\mathrm{O}: \mathrm{C}<0.8$ depends on the types of organic functional groups and inorganic salts presented. Therefore, these studies suggest that the LLPS in the mixed organic and inorganic components aerosol particles is influenced by the amount of organic and inorganic aerosol components and their types.

In this work, AS is chosen as a test substance because it is a major component of the atmospheric aerosol and its thermodynamic behavior is well characterized. Most importantly, ammonium sulfate particles are stable and not volatile, which are useful features for HTDMA studies. We investigated the effect of different coating PA thickness and AS core size on the water uptake of core-shell-generated particles and further studied the effect of the mixing states on the hygroscopic behavior of PA/AS aerosol particles using the HTDMA technique. For example, we compared the hygroscopic behavior of initially well-mixed AS / PA particles with that of core-shell-generated AS / PA particles with the same PA mass fractions. In addition, we used the ZdanovskiiStokes-Robinson (ZSR) relation to predict the hygroscopic growth factor (GF) of mixed aerosol particles in the different mixing structure. Moreover, the Aerosol Inorganic-Organic Mixtures Functional groups Activity Coefficients (AIOMFAC) model (Zuend et al., 2008, 2011), with a version of the liquid-liquid equilibrium (LLE) algorithm, was employed in our study to predict the phase compositions of liquid and solid phases for a given mixture composition (Zuend and Seinfeld, 2013).

\section{Experimental and modeling methods}

\subsection{HTDMA setup and experimental protocol}

The HTDMA setup is employed to measure the aerosol nanoparticle hygroscopic growth factor $\left(g_{\mathrm{f}}\right)$ and phase transition in the RH range from $5 \%$ to $90 \%$. Here, $g_{\mathrm{f}}$ is defined as the ratio of the mobility diameter of aerosol particles after humidification $\left(D_{\mathrm{m}}(\mathrm{RH})\right)$ to the dry condition $\left(D_{\mathrm{m}}(<5 \% \mathrm{RH})\right)$. Figure 1 shows a schematic diagram of the HTDMA setup. It is comprised of four main components, including three dif-

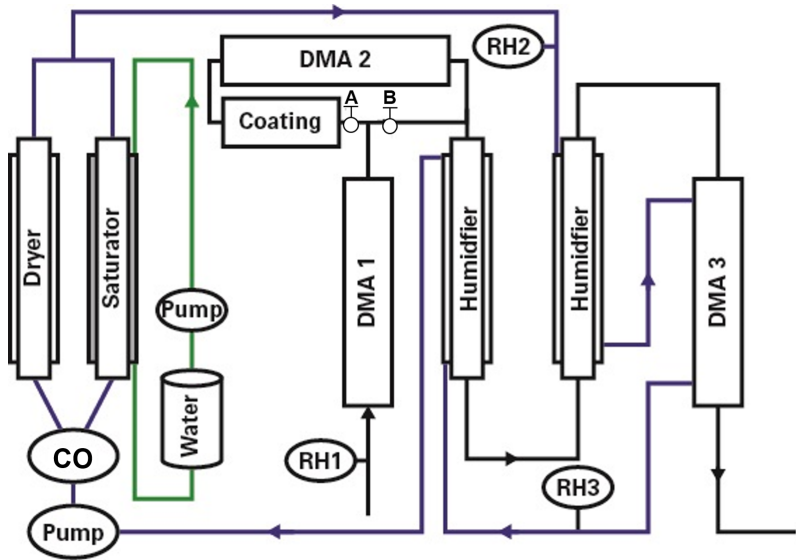

Figure 1. Schematic diagram of the coating hygroscopicity tandem differential mobility analyzer. Here, CO is the critical orifice, DMA is the differential mobility analyzer, and RH1 and RH2 (measured $\mathrm{RH}$ sensor) represent the $\mathrm{RH}$ of the aerosol and humidified flow in the inlet of DMA1 and the humidifier, respectively. RH3 (measured by dew point mirror) represents the $\mathrm{RH}$ of excess air. Valve $\mathrm{B}$ is open and valve $\mathrm{A}$ is closed to the homogeneous internally mixedmode experiment. Valve A is open and Valve B is closed to the coating-mode experiment. Black line: aerosol line. Blue line: sheath line. Green line: Milli-Q water.

ferential mobility analyzers (DMAs), a condensation particle counter (CPC), a humidification system, and a coating system. More detailed information on the HTDMA setup, calibration, and verification has been described elsewhere (Lei et al., 2014, 2018; Jing et al., 2016; Liu et al., 2016). In our study, the particle-sizing, aerosol/ sheath flow rates, and DMA voltage supply were calibrated every month. The uncertainty of aerosol/ sheath flow rates is kept within $\pm 1 \%$ of the reference values. The deviations of the measured DMA voltages from set-point values are less than $\pm 1 \%$. The sizing agreement of the DMAs between the measured diameter of polystyrene latex (PSL) spheres and their nominal diameter $(100 \pm 3 \mathrm{~nm})$ is within $\pm 1 \%$. Thus, the calculated uncertainty of growth factor depends on the error propagation formula $\sqrt{\left(\left(g_{\mathrm{f}} \frac{\sqrt{2} \varepsilon_{D_{p}}}{D_{p}}\right)^{2}+\left(\varepsilon_{\mathrm{RH}} \frac{d g_{\mathrm{f}}}{d \mathrm{RH}}\right)^{2}\right)}$ (Mochida and Kawamura, 2004). Here, $\varepsilon_{D_{p}}, \varepsilon_{\mathrm{RH}}$, and $g_{\mathrm{f}}$ are the uncertainty of particle mobility diameter, relative humidity, and growth factor at different RH, respectively. The average sizing offsets of our system are taken here as $\frac{\varepsilon_{D_{p}}}{D_{p}}$. Also, the RH uncertainty is the accuracy of the RH sensor $( \pm 2 \%)$. In this study, the calculated uncertainty of the growth factor of AS / PA aerosol particles is $\sim 1 \%-2 \%$. The chemical substances and related physical properties are available in Table S1 in the Supplement. The solutions used in our measurements are prepared with distilled and deionized Milli-Q water (resistivity of $18.2 \mathrm{M} \Omega \mathrm{cm}$ at $298 \mathrm{~K})$. 


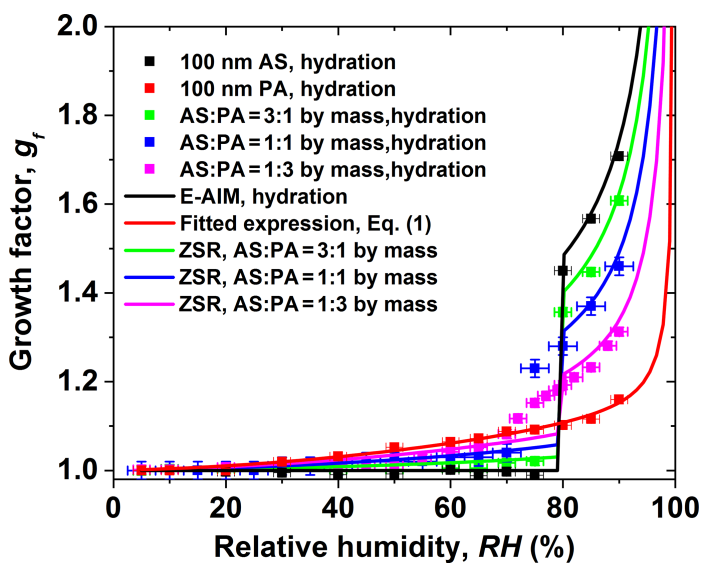

Figure 2. The hygroscopic growth factor for $100 \mathrm{~nm}$ (dry diameter, $\mathrm{RH}<5 \%$ ) aerosol particles containing ammonium sulfate (AS), phthalic acid (PA), and initially well-mixed mixtures of PA and AS with different mass ratios of AS to PA. In comparison, the E-AIM model, the fitted expression Eq. (1), and the ZSR relation predicted growth factors of AS, PA, and initially well-mixed particles with different mass fractions of PA, respectively.

\subsubsection{Initially well-mixed AS / PA aerosol particles}

Briefly, polydisperse aerosol particles were atomized from homogeneous bulk solutions with different mass fractions of PA and AS (Fig. 1), assuming that the compositions of aerosol particles remain the same as that of the solutions used in the atomizer (MSP 1500, MSP). Due to the morphology and mixing state of AS / PA aerosol particles generated by an initially well-mixed aqueous solution, as indicated at dry RH in Fig. S2 in the Supplement, note that aerosol particles generated this way are referred to as initially well-mixed aerosol particles. The resulting particles were dried and subsequently charged through a dryer and then a neutralizer, respectively. A monodisperse distribution of particles with a desired diameter was selected by the first differential mobility analyzer (DMA1) with RH below 5\%. After particle sizing, the aerosol particles were exposed to a humidification mode $(5 \% \rightarrow 90 \%)$ in the Nafion conditioner tubes. The number size distributions of humidified aerosol particles were then measured by a DMA3 coupled with a CPC. To have precise control of the aerosol RH, the flow rates of the humid and dry air were adjusted with a proportional-integral-derivative (PID) system. Also, to ensure sufficient water equilibrium with aerosol particles, the difference between $\mathrm{RH} 2$ and $\mathrm{RH} 3$ (RH in the sheath flow) was within $2 \%$ during the experiment.

\subsubsection{Core-shell-generated AS / PA aerosols}

The AS core aerosol particles were generated from an aqueous solution of AS $(0.05 \mathrm{wt} \%)$ by an atomizer. After passage through a silica gel diffusion dryer and a neutralizer, the AS core aerosol particles with a certain diameter $(100,150$, and
Table 1. Coefficients of the fitted growth curve parameterization to measured growth factor data using Eq. (1).

\begin{tabular}{lrrr}
\hline Chemical compound & a & $b$ & $c$ \\
\hline Phthalic acid & 0.083116 & 0.291473 & -0.353544 \\
\hline
\end{tabular}

$200 \mathrm{~nm}$, respectively) were first selected by the DMA1 and then exposed to organic vapors in a coating system. To be specific, the coating system contains a controlled silicone oil bath vaporizer, a reservoir of organic compound, and a condenser. The AS core particles passed through a sealed flask immersed in a silicone oil bath. The sealed flask was filled with the PA powder. The PA vapors were enriched into the aerosol flow by heating. The temperature required for vaporizing PA is between $\sim 100$ and $\sim 130^{\circ} \mathrm{C}$, which corresponds to a coating thickness between 10 and $50 \mathrm{~nm}$. The resulting organic vapors were condensed onto the AS core particles after cooling to an ambient environment through a condenser. Similarly, this system for coating organic components on the particles has been proven to be efficient by Abo Riziq et al. (2008). The coated particles of a certain size were then selected by the DMA2 to determine the thickness of organic components ( $D_{\text {total }}=D_{\text {core }}+$ coating $)$. After coreshell-generated particle sizing, aerosols were prehumidified in a Nafion tube and flowed into the second Nafion humidifier at the set RH2 to reach equilibrium for the growth of aerosol particles. Finally, the humidified core-shell-generated particles were detected by the DMA3 and CPC at ambient temperature. The uncertainty of the thickness of coating PA is $\pm 1.0 \mathrm{~nm}$, considering the fluctuation in temperature and uncertainty of sizing measurements by the DMAs. Due to the morphology and mixing state of AS / PA aerosol particles generated by a coating HTDMA at dry RH, note that aerosol particles generated this way are referred to as core-shellgenerated aerosol particles.

\subsection{Theory and modeling methods}

\subsubsection{GF data fit}

We use the following expression to predict the hygroscopic growth factor of individual components:

$\mathrm{GF}=\left[1+\left(a+b \cdot a_{\mathrm{w}}+c \cdot a_{\mathrm{w}}^{2}\right) \frac{a_{\mathrm{w}}}{1-a_{\mathrm{w}}}\right]^{\frac{1}{3}}$.

Here, it is assumed that water activity $\left(a_{\mathrm{w}}\right)$ is equal to the water saturation ratio $\left(a_{\mathrm{w}}=\mathrm{RH} / 100 \%\right)$. The coefficients a, $\mathrm{b}$, and $\mathrm{c}$ are determined by fitting Eq. (1), and their values are shown in Table 1 according to the measured GF data against RH. Eq. (1) is expected to fit the continuous water uptake behavior of the particles (Brooks et al., 2004; Kreidenweis et al., 2005). 


\subsubsection{GF predictions by ZSR}

We use the ZSR relation to calculate the hygroscopic growth factor of mixed particles, $\mathrm{GF}_{\text {mixed }}$. The GF of a mixture can be estimated from the $\mathrm{GF}_{j}$ of the pure components $j$ and their respective volume fractions, $\varepsilon_{j}$, in the mixture (Malm and Kreidenweis, 1997). $R_{A S}$ is the radius of the core and $R_{\text {core-shell }}$ is the radius of the core-shell-generated aerosol.

$$
\begin{aligned}
& \mathrm{GF}_{\text {mix }}=\left[\sum_{j} \varepsilon_{j}\left(\mathrm{GF}_{j}\right)^{3}\right]^{\frac{1}{3}} \\
& \varepsilon_{A S}=\frac{\frac{4}{3} \pi R_{A S}^{3}}{\frac{4}{3} \pi R_{\text {core-shell }}^{3}}
\end{aligned}
$$

\section{Results and discussion}

\subsection{Hygroscopic growth of initially well-mixed aerosol particles}

Figure 2 shows the measured hygroscopic growth factors of the AS, PA, and initially well-mixed AS with different mass fractions of PA particles with dry diameter $100 \mathrm{~nm}$ against $\mathrm{RH}$, respectively. During the hydration mode, there is no change in size until a slow increase occurs at $60 \% \mathrm{RH}$ in the case of initially well-mixed AS/PA aerosol particles. This increase may occur because the PA uptakes a small amount of water. However, an abrupt increase in the hygroscopic growth factor is observed at $75 \% \mathrm{RH}$ for initially well-mixed particles containing $50 \mathrm{wt} \%$ and $75 \mathrm{wt} \% \mathrm{PA}$, of which the growth factor is higher than that of pure PA aerosol particles $(1.09 \pm 0.01 \mathrm{~nm}$ from measurements shown in Fig. 2) at the same RH. An interesting yet contrasting phenomenon is that water uptake for initially well-mixed particles containing $50 \mathrm{wt} \%$ PA components is relatively higher than that of mixtures containing $75 \mathrm{wt} \% \mathrm{PA}$ at $75 \% \mathrm{RH}$. One possible reason is that the full deliquescence of AS in the initially wellmixed particles with $50 \mathrm{wt} \%$ PA components is completed at $75 \% \mathrm{RH}$, while AS in the mixtures containing $75 \mathrm{wt} \% \mathrm{PA}$ components is partially deliquescent. A decrease in the hygroscopic growth factor of initially well-mixed AS / PA particles with increasing mass fractions of PA is observed at RH above $80 \%$. For example, the measured growth factors for initially well-mixed aerosol particles containing $25 \mathrm{wt} \%$, $50 \mathrm{wt} \%$, and $75 \mathrm{wt} \% \mathrm{PA}$ are $1.36,1.28$, and 1.19 at $80 \% \mathrm{RH}$, respectively, lower than the growth factor of 1.45 for pure deliquesced AS particles (value from measurements shown in Fig. 2) at the same RH. Also, the measured hygroscopic growth factors within experimental uncertainty were in good agreement with the results from the initially well-mixed particles performed by Hämeri et al. (2002). In addition, with increasing mass fractions of PA in the initially well-mixed particles, the smoothing of the hygroscopic growth factor curves is obvious, indicating that the PA aerosol particles have a significant effect on the water uptake of initially well- mixed AS / PA particles, such as a shift or suppression of the DRH of AS in the mixed particles. For example, in the case of $1: 3$ mixtures of AS : PA (by mass), $75 \mathrm{wt} \% \mathrm{PA}$ in the initially well-mixed particles suppresses the deliquescence of AS; i.e., AS in the initially well-mixed particles slowly dissolves into the liquid phase due to continuous water uptake of PA prior to the deliquescence relative humidity of AS ( $80 \% \mathrm{RH})$. This similar phenomenon was observed in previous studies (e.g., Hämeri et al., 2002; Qiu and Zhang, 2013). For example, Qiu and Zhang (2013) observed that mixture particles consisting of dimethylaminium sulfate and AS exhibited a moderate growth by water uptake in the $\mathrm{RH}$ range of $40 \%-70 \% \mathrm{RH}$. The calculated growth factors from a model based on the ZSR relation agree well with the hygroscopic growth factors of initially well-mixed AS / PA particles when accounting for measurement uncertainty. A possible reason for this good agreement is that the measured growth factors referring to the water uptake contribution by PA in the ZSR relation are obtained from the fitted growth curve of pure PA particles (as shown in Fig. 2; fitted expression, Eq. 1). Thus, in the case of initially well-mixed AS / PA, relatively good agreement with the experimental growth factors of mixtures with $25 \mathrm{wt} \%, 50 \mathrm{wt} \%$, and $75 \mathrm{wt} \% \mathrm{PA}$ demonstrates that individual components independently absorb water in proportion to their volume. However, the discrepancy between the measured growth factor of initially well-mixed AS / PA particles at $75 \% \mathrm{RH}$ and the predicted growth factors using the ZSR relation may be due to the molecular interactions between organic molecules and completely or partially dissolved AS ions. A similar phenomenon was reported for well-mixed mixtures of AS + levoglucosan in the previous study by Lei et al. (2014, 2018). In addition, the use of the AIOMFAC LLE model to predict the LLPS and RH-dependent water content of AS / PA particles containing $46 \mathrm{wt} \%$ PA under hydration conditions. As shown in Fig. S3 in the Supplement, at low RH, AS forms a crystalline phase prior to its deliquescence. Thus, AS is predominantly partitioned to the solid phase $(\delta)$, while PA is found in a separate amorphous/liquid phase that further contains water (in solid-liquid equilibrium) up to the complete AS deliquescence at $\sim 79 \% \mathrm{RH}$. Two liquid phases, one AS-rich $(\alpha)$ and one PA-rich $(\beta)$, are predicted to coexist between $79 \%<\mathrm{RH}<96 \%$ in the hydration case. At RH above $96 \%$, a single liquid phase is the stable state, although we note that AIOMFAC LLE may have an uncertainty of several \% RH in terms of the RH range in which LLPS is predicted (Song et al., 2012a, b).

\subsection{Hygroscopic growth of core-shell-generated structured aerosol particles}

Figure 3 shows the measured hygroscopic growth of coreshell-generated structured particles as a function of RH. Here, we investigated the hygroscopic behavior of samples of various AS core particle sizes (AS particle dry diameter of 
100,150 , and $200 \mathrm{~nm}$ ) and coating (PA coating of 10, 20, 30, and $50 \mathrm{~nm}$ ), respectively. The core-shell-generated structured particles start to absorb a small amount of water at RH lower than the DRH of AS due to the organic coating. A similar behavior has been observed for core-shell-generated structured particles containing AS and palmitic acid by Garland et al. (2005), where early water uptake and reduced hygroscopic growth after deliquescence of AS (compared to pure AS aerosols) were reported. A reduction of the hygroscopic growth factors of core-shell-generated particles becomes obvious as the thickness of the PA shell increases after the deliquescence of core-shell-generated particles. For example, the measured growth factor value at $80 \% \mathrm{RH}$ is $1.45,1.40$, 1.32, and 1.28 for core-shell-generated particles containing $100 \mathrm{~nm}$ AS and 10, 20, 30, and $50 \mathrm{~nm}$ coating PA shell, respectively. The kinetic limitation on the core-shell-generated particles is expected to increase considerably with increasing the thickness of the coating PA shells, which retards the transport rate of water molecules across core-shell-generated aerosol particles-air interface. In addition, the measured hygroscopic growth factor of core-shell-generated AS / PA mixtures is predicted by the ZSR relation, which is based on the hygroscopic growth factors of AS and PA derived from the E-AIM predictions for AS and the fitted GF curve (Eq. 1). The ZSR-based predictions are lower than that of core-shellgenerated aerosol particles at RH in the range of 5\%-90\%. The underprediction of the ZSR relation was also observed in the literature (Chan et al., 2006; Sjogren et al., 2007). Sjogren et al. (2007) observed an enhanced water uptake of mixtures consisting of AS and adipic acid with different mass ratios $(1: 2,1: 3$, and $1: 4)$ at RH above $80 \%$ compared with the ZSR relation in the hydration condition. They assumed that adipic acid is more likely to enclose the water-soluble AS in veins and cavities, which results in easy uptake of water and a negative curvature of the solution meniscus at the opening of the vein compared to a flat or convex particle surface. Therefore, in the case of AS / PA core-shell-generated particles, one potential reason for the underestimation of the measured growth factor by ZSR relation is the morphology effect on the core-shell-generated structured AS / PA particle. To be specific, due to the potential presence of polycrystalline AS containing pores, cracks, and veins (Zelenyuk et al., 2006; Sjogren et al., 2007) when RH approaches $80 \%$, these pores or veins may fill with aqueous PA solution. Thus, water molecules may be easier to diffuse to the veins or pores than the particle surface. At RH above $80 \%$, deliquesced AS is more likely to mixed partially to an aqueous solution PA. The resulting effect of the arrangement and restructuring of core-shell structured particles may change the hygroscopicity, morphology, and mixing state of the core-shell-generated particles (Chan et al., 2006; Sjogren et al., 2007).

Figure 4 shows the experimental water absorption of the varying size of the AS core coated with a $50 \mathrm{~nm}$ PA shell in the hydration condition. In the case of a $50 \mathrm{~nm}$ PA shell coated with a certain size of the AS core $(100,150$, and
$200 \mathrm{~nm}$ ) with respect to $68 \mathrm{wt} \%, 55 \mathrm{wt} \%$, and $46 \mathrm{wt} \% \mathrm{PA}$ in the core-shell-generated particles, it exhibits an increase in the hygroscopic growth factor of core-shell-generated particles at RH below $80 \%$ as the size of AS core decreases. However, a decrease in the hygroscopic growth factor of coreshell-generated mixtures is observed at RH above $80 \%$ with decreasing the size of the AS core. This indicates that the $50 \mathrm{~nm}$ PA shell in the core-shell-generated particles has predominantly contributed to the hygroscopic growth of coreshell-generated particles at low RH. At high RH (e.g., after AS deliquescence), however, a $50 \mathrm{~nm}$ PA coating shows weak kinetic limitations for water uptake by core-shell-generated particles as the size of AS core increases. For example, the measured growth factor values are 1.28, 1.34, and 1.40 at $80 \%$ RH for $100-200 \mathrm{~nm}$ AS core in the mixed particles, respectively. The discrepancy between measured hygroscopic growth factors and predicted hygroscopic growth factors of core-shell-generated particles by the ZSR relation, as discussed in Sect. 3.2, is due to the morphology effect. For the ZSR prediction, it assumes that the volume fraction of AS components is constant according to the ratio of the volume of AS core in the sphere to the volume of a coreshell-generated sphere based on Eq. (3). Without considering the morphology effect, the ZSR prediction results in an underestimation of hygroscopic growth factors of core-shellgenerated particles.

\subsection{Comparison of core-shell-generated and initially well-mixed AS / PA aerosol particles}

Figure 5 shows the hydration curves of different AS cores coated with different mass fractions of PA loading (shown in Table S2 in the Supplement) in comparison with those of the initially well-mixed with the same PA mass fraction particles, pure AS particles, and pure PA particles in the range of 5\%-90\% RH. The effect of the coating PA on core-shellgenerated particles becomes more pronounced than that of PA in the initially well-mixed particles at RH below $70 \%$, as shown in Fig. 5a, b, which leads to higher amounts of water absorption at low RH. However, compared to Fig. 5a, b, Fig. $5 \mathrm{c}$ shows that the hygroscopic growth factors of initially well-mixed AS / PA are slightly higher than that of AS / PA core-shell-generated particles with $46 \mathrm{wt} \% \mathrm{PA}$. At $75 \% \mathrm{RH}$, the measured growth factor value of core-shell-generated particles is lower than that of internally well-mixed mixtures in the PA mass fraction range from $68 \mathrm{wt} \%$ to $46 \mathrm{wt} \%$ due to the mass transfer limitations of water vapor transport to the AS core in the core-shell-generated particles. For the initially well-mixed AS / PA particles, however, partial dissolution of AS into the liquid PA phase may lead to more water uptake by initially well-mixed particles. For example, for the core-shell-generated mixtures with $68 \mathrm{wt} \% \mathrm{PA}$ loading, the experimental growth factor value is 1.09 at $75 \% \mathrm{RH}$, relative to the growth factor of 1.17 for initially well-mixed mixtures of AS / PA. After an abrupt increase in particle diameter 

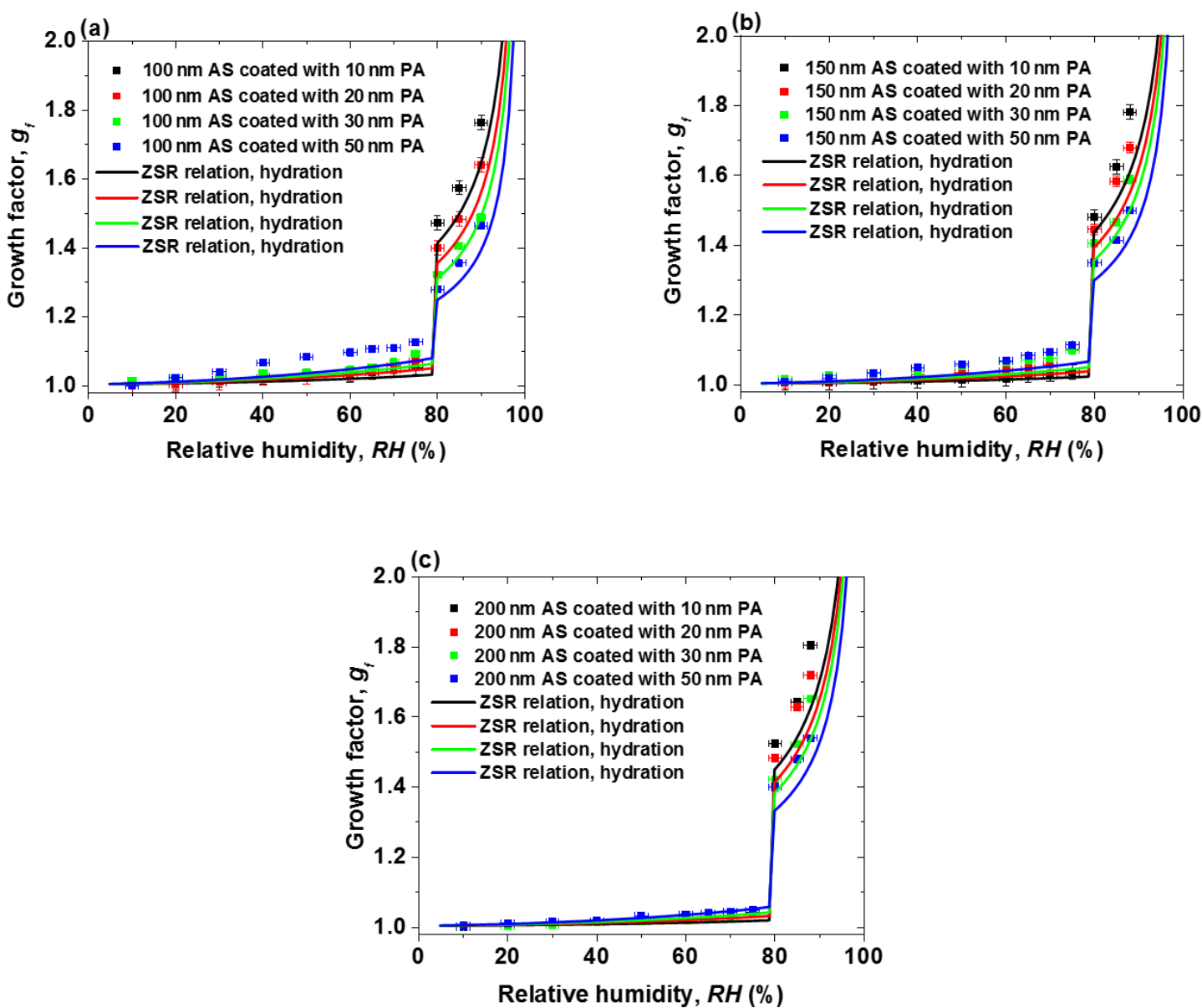

Figure 3. The hygroscopic growth factor for core-shell-generated ammonium sulfate (AS) and phthalic acid (PA) aerosol particles. In comparison, the ZSR relation predicted growth factor of core-shell-generated aerosol particles: (a) $100 \mathrm{~nm}$ AS core, (b) $150 \mathrm{~nm}$ AS core, (c) $200 \mathrm{~nm}$ AS core.

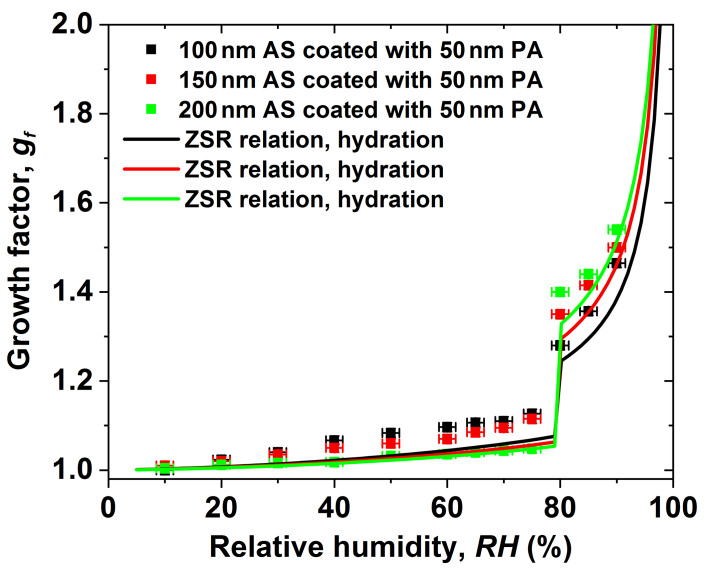

Figure 4. The hygroscopic growth factor for 100-200 nm ammonium sulfate (AS) core with a $50 \mathrm{~nm}$ phthalic acid (PA) coating. In comparison, the ZSR relation predicted growth factor of core-shellgenerated aerosol particles with different AS cores. of mixed particles, the core-shell-generated AS / PA particles uptake slightly more water than initially well-mixed AS / PA with the same mass fractions of PA as RH increases above $80 \%$. Accordingly, at high RH, the occurrence of microscopic restructuring of core-shell-generated particles may affect their size. A similar hygroscopic behavior was observed in previous papers (Chan et al., 2006; Sjogren et al., 2007; Maskey et al., 2014). Chan et al. (2006) investigated hygroscopicity of $49 \mathrm{wt} \%$ glutaric acid coated on AS core during two continuous hydration cycles: the experimental growth factor of the fresh core-shell of AS and glutaric acid in the first hydration cycle is slightly higher than those in the second hydration cycle with the same mass fractions of glutaric acid. They suggested that the mixing state has changed from core-shell to well-mixed state during the humidification process. Also, a slightly higher growth factor of core-shell particles than well-mixed particles was found when comparing the hygroscopic growth factors of $49 \mathrm{wt} \%$ glutaric acid coated on AS core with that of well-mixed mixtures of AS with the same mass fractions of glutaric acid from differ- 

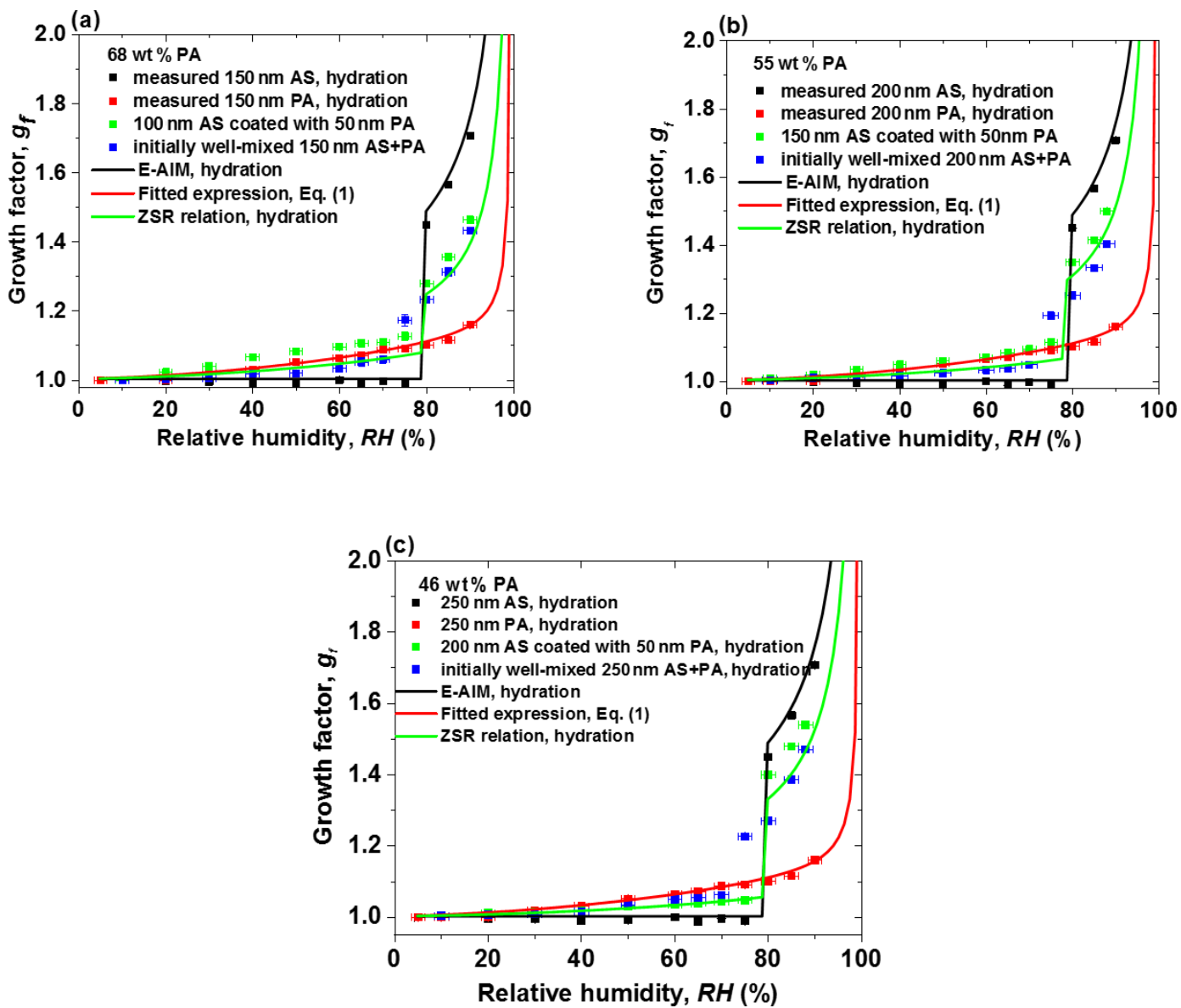

Figure 5. The hygroscopic growth factor for core-shell-generated and initially well-mixed aerosol particles with the same dry mass fractions of phthalic acid (PA) containing (a) $68 \mathrm{wt} \% \mathrm{PA}$, (b) $55 \mathrm{wt} \% \mathrm{PA}$, and (c) $46 \mathrm{wt} \%$ PA. In comparison, the E-AIM model, the fitted expression Eq. (1), and the ZSR relation predicted growth factors of ammonium sulfate (AS), PA, and internally well-mixed particles with different mass fractions of PA, respectively.

ent papers (Choi et al., 2002; Chan et al., 2006). However, a contrasting phenomenon was observed in the previous study (Maskey et al., 2014). Maskey et al. (2014) investigated the hygroscopic behavior of the internal mixtures consisting of AS coated with either succinic acid or levoglucosan in the different mixing state with the same volume fractions of organic compounds. The growth factor of core-shell particles consisting of AS and succinic acid is lower than that of the well-mixed particles, while experimental values for the coreshell of AS / levoglucosan particles are close to those of the well-mixed mixtures. The possible reasons for the difference between our study and results from Maskey et al. (2014) are the physical properties of the organic components, such as hygroscopicity, viscosity, volatility, and water uptake coefficients. Therefore, different kinds of organic compounds have a different effect in the hygroscopic growth of mixtures, including the core-shell and the well-mixed state. For example, no hygroscopic growth was observed up to $99 \% \mathrm{RH}$ for pure succinic acid particles (shown in Fig. S1a in the Supplement). Peng et al. (2001) measured the DRH of suc- cinic acid at $99 \% \mathrm{RH}$ using a bulk solution at $24^{\circ} \mathrm{C}$. Also, Henning et al. (2012) observed no hygroscopic growth of soot / succinic acid core-shell particles in the hydration mode using HTDMA. In the case of AS/ succinic acid core-shell particles, no water uptake by the AS-coated succinic acid shell was observed before $80 \% \mathrm{RH}$, while there is a gradual increase in water absorption of core-shell-generated particles prior to the deliquescence of AS with different mass fraction of PA components, as shown in Fig. 5a-c. This suggested that the physical state of the shell is solid and liquid for the Maskey et al. (2014) and our measurements, respectively. At RH above $80 \%$, the kinetic limitation on the water vapor uptake through solid shell into the core is more obvious than that through liquid shell into the core (i.e., the liquid diffusion coefficient of water vapor is in the range of $10^{-10}$ to $10^{-9} \mathrm{~m}^{2} \mathrm{~s}^{-1}$ and the solid diffusion coefficient of water vapor is in the range of $10^{-13}-10^{-14} \mathrm{~m}^{2} \mathrm{~s}^{-1}$ at $25^{\circ} \mathrm{C}$ ). This can lead to different hygroscopic behavior of coreshell particles. In the case of AS / levoglucosan measured by Maskey et al. (2014), they found slightly higher growth fac- 
tors for well-mixed particles than core-shell aerosol particles ( $88 \mathrm{~nm}$ AS core coated by $12 \mathrm{~nm}$ levoglucosan). The mass fraction of levoglucosan in the core-shell-generated particles is $\sim 29 \mathrm{wt} \%$. In our study, AS is coated with PA with a mass fraction range between $46 \mathrm{wt} \%$ and $68 \mathrm{wt} \%$. Next, using a low mass fraction of PA (e.g., $29 \mathrm{wt} \%$ ) in coreshell-generated aerosol particles is to be investigated. In addition, for the AS / PA mixture aerosol particles containing $46 \mathrm{wt} \%-68 \mathrm{wt} \% \mathrm{PA}$, the measured growth factors of initially well-mixed AS / PA particles are in good agreement with the ZSR relation prediction compared with that of core-shellgenerated AS / PA particles.

\section{Summary and conclusion}

In this study, we focused on PA to represent common organic compounds produced by various sources (e.g., vehicles, biomass burning, photo-oxidation). It is found that PA aerosol particles uptake water continuously as RH increases. We further investigated the effect of a PA coating on the hygroscopicity of core-shell-generated aerosol particles. As PA coating thickness increases, the hygroscopic growth factor of AS / PA core-shell-generated particles increases prior to the deliquescence of AS, but the water uptake decreases at $\mathrm{RH}$ above $80 \%$. Furthermore, we compared the hygroscopic behavior of AS / PA core-shell-generated particles with that of AS / PA initially well-mixed particles. Due to mixing state effects, higher hygroscopic growth factors of AS / PA coreshell-generated particles, compared to that of initially wellmixed particles, were observed in this study at RH above $80 \%$. In addition, the ZSR relation prediction is in good agreement with measured results of AS / PA initially wellmixed particles but leads to the underestimation of the hygroscopic growth factor of AS / PA core-shell-generated particles at RH above $80 \%$. We attribute these discrepancies to the morphology effect when AS deliquesces in the coreshell-generated particles.

There is a vast number of internally mixed organicinorganic aerosol particles existing in the atmosphere. The hygroscopicity behavior of mixture particles exhibits variability during RH cycles depending on the chemical composition, size, and mixing state. Humidity cycles may lead to LLPS, e.g., in the form of core-shell aerosol particles, including at higher RH or in the salt-supersaturated concentration range. Also, due to the different physicochemical properties of organic compounds (e.g., viscosity, solubility, physical state, and morphology), the equilibrium time varies for these organic coated with inorganic aerosol particles. Therefore, potential kinetic limitations in the HTDMA-measured hygroscopicity of core-shell aerosol particles are to be investigated in both humidification and dehumidification conditions.
Data availability. Readers who are interested in the data should contact Ting Lei (ting.lei@mpic.de).

Supplement. The supplement related to this article is available online at: https://doi.org/10.5194/acp-21-2179-2021-supplement.

Author contributions. WGW designed and led the study. WGW and TL assembled the coating HTDMA. TL performed the experiments and then wrote the manuscript. WGW supported the experiments. All coauthors discussed the results and commented on the manuscript.

Competing interests. The authors declare that they have no conflict of interest.

Acknowledgements. This project was supported by The National Key Research and Development Program of China (2017YFC0209500) and the National Natural Science Foundation of China (91544227, 41822703).

Financial support. This research was supported by the National Key Research and Development Program of China (grant no. 2017YFC0209500) and the National Natural Science Foundation of China (grant nos. 41822703, 91744204, and 91844301).

Review statement. This paper was edited by Annele Virtanen and reviewed by three anonymous referees.

\section{References}

Abo Riziq, A., Erlick, C., Dinar, E., and Rudich, Y.: Optical properties of absorbing and non-absorbing aerosols retrieved by cavity ring down (CRD) spectroscopy, Atmos. Chem. Phys., 7, 15231536, https://doi.org/10.5194/acp-7-1523-2007, 2007.

Abo Riziq, A., Trainic, M., Erlick, C., Segre, E., and Rudich, Y.: Extinction efficiencies of coated absorbing aerosols measured by cavity ring down aerosol spectrometry, Atmos. Chem. Phys., 8 , 1823-1833, https://doi.org/10.5194/acp-8-1823-2008, 2008.

Ansari, A. S. and Pandis, S. N.: Water Absorption by Secondary Organic Aerosol and Its Effect on Inorganic Aerosol Behavior, Environ. Sci. Technol., 34, 71-77, 2000.

Bertram, A. K., Martin, S. T., Hanna, S. J., Smith, M. L., Bodsworth, A., Chen, Q., Kuwata, M., Liu, A., You, Y., and Zorn, S. R.: Predicting the relative humidities of liquid-liquid phase separation, efflorescence, and deliquescence of mixed particles of ammonium sulfate, organic material, and water using the organic-to-sulfate mass ratio of the particle and the oxygen-tocarbon elemental ratio of the organic component, Atmos. Chem. Phys., 11, 10995-11006, https://doi.org/10.5194/acp-11-109952011, 2011. 
Brooks, S. D., DeMott, P. J., and Kreidenweis, S. M.: Water uptake by particles containing humic materials and mixtures of humic materials with ammonium sulfate, Atmos. Environ., 38, 18591868, 2004.

Chan, M. N., Lee, A. K. Y., and Chan, C. K.: Responses of ammonium sulfate particles coated with glutaric acid to cyclic changes in relative humidity: Hygroscopicity and Raman characterization, Environ. Sci. Technol., 40, 6983-6989, 2006.

Cheng, Y. F., Wiedensohler, A., Eichler, H., Heintzenberg, J., Tesche, M., Ansmann, A., Wendisch, M., Su, H., Althausen, D., Herrmann, H., Gnauk, T., Brüggemann, E., Hu, M., and Zhang, Y. H.: Relative humidity dependence of aerosol optical properties and direct radiative forcing in the surface boundary layer at Xinken in Pearl River Delta of China: An observation based numerical study, Atmos. Environ., 42, 6373-6397, 2008.

Choi, M. Y. and Chan, C. K.: The Effects of Organic Species on the Hygroscopic Behaviors of Inorganic Aerosols, Environ. Sci. Technol., 36, 2422-2428, 2002.

Ciobanu, V. G., Marcolli, C., Krieger, U. K., Weers, U., and Peter, T.: Liquid-Liquid Phase Separation in Mixed Organic/Inorganic Aerosol Particles, J. Phys. Chem. A, 113, 10966-10978, 2009.

Ditas, J., Ma, N., Zhang, Y., Assmann, D., Neumaier, M., Riede, H., Karu, E., Williams, J., Scharffe, D., Wang, Q., Saturno, J., Schwarz, J. P., Katich, J. M., McMeeking, G. R., Zahn, A., Hermann, M., Brenninkmeijer, C. A. M., Andreae, M. O., Pöschl, U., Su, H., and Cheng, Y.: Strong impact of wildfires on the abundance and aging of black carbon in the lowermost stratosphere, P. Natl. Acad. Sci. USA, 115, E11595-E11603, https://doi.org/10.1073/pnas.1806868115, 2018.

Eichler, H., Cheng, Y. F., Birmili, W., Nowak, A., Wiedensohler, A., Brüggemann, E., Gnauk, T., Herrmann, H., Althausen, D., Ansmann, A., Engelmann, R., Tesche, M., Wendisch, M., Zhang, Y. H., Hu, M., Liu, S., and Zeng, L. M.: Hygroscopic properties and extinction of aerosol particles at ambient relative humidity in South-Eastern China, Atmos. Environ., 42, 6321-6334, 2008.

Falkovich, A. H., Schkolnik, G., Ganor, E., and Rudich, Y.: Adsorption of organic compounds pertinent to urban environments onto mineral dust particles, J. Geophys. Res.-Atmos., 109, D02208, https://doi.org/10.1029/2003JD003919, 2004.

Ganguly, D., Jayaraman, A., Rajesh, T. A., and Gadhavi, H.: Wintertime aerosol properties during foggy and nonfoggy days over urban center Delhi and their implications for shortwave radiative forcing, J. Geophys. Res.-Atmos., 111, D15217, https://doi.org/10.1029/2005JD007029, 2006.

Garland, R. M., Wise, M. E., Beaver, M. R., DeWitt, H. L., Aiken, A. C., Jimenez, J. L., and Tolbert, M. A.: Impact of palmitic acid coating on the water uptake and loss of ammonium sulfate particles, Atmos. Chem. Phys., 5, 1951-1961, https://doi.org/10.5194/acp-5-1951-2005, 2005.

Gupta, D., Kim, H., Park, G., Li, X., Eom, H.-J., and Ro, C.U.: Hygroscopic properties of $\mathrm{NaCl}$ and $\mathrm{NaNO}_{3}$ mixture particles as reacted inorganic sea-salt aerosol surrogates, Atmos. Chem. Phys., 15, 3379-3393, https://doi.org/10.5194/acp-153379-2015, 2015.

Hämeri, K., Charlson, R., and Hansson, H.-C.: Hygroscopic properties of mixed ammonium sulfate and carboxylic acids particles, AICHE J., 48, 1309-1316, 2002.
Heintzenberg, J., Maßling, A., and Birmili, W.: The connection between hygroscopic and optical particle properties in the atmospheric aerosol, Geophys. Res. Lett., 28, 3649-3651, 2001.

Henning, S., Ziese, M., Kiselev, A., Saathoff, H., Möhler, O., Mentel, T. F., Buchholz, A., Spindler, C., Michaud, V., Monier, M., Sellegri, K., and Stratmann, F.: Hygroscopic growth and droplet activation of soot particles: uncoated, succinic or sulfuric acid coated, Atmos. Chem. Phys., 12, 4525-4537, https://doi.org/10.5194/acp-12-4525-2012, 2012.

Hodas, N., Zuend, A., Mui, W., Flagan, R. C., and Seinfeld, J. H.: Influence of particle-phase state on the hygroscopic behavior of mixed organic-inorganic aerosols, Atmos. Chem. Phys., 15, 5027-5045, https://doi.org/10.5194/acp-15-5027-2015, 2015.

Hori, M., Ohta, S., Murao, N., and Yamagata, S.: Activation capability of water soluble organic substances as CCN, J. Aerosol Sci., 34, 419-448, 2003.

Huff Hartz, K. E., Tischuk, J. E., Chan, M. N., Chan, C. K., Donahue, N. M., and Pandis, S. N.: Cloud condensation nuclei activation of limited solubility organic aerosol, Atmos. Environ., 40, 605-617, 2006.

Jing, B., Tong, S., Liu, Q., Li, K., Wang, W., Zhang, Y., and Ge, M.: Hygroscopic behavior of multicomponent organic aerosols and their internal mixtures with ammonium sulfate, Atmos. Chem. Phys., 16, 4101-4118, https://doi.org/10.5194/acp-164101-2016, 2016.

Kawamura, K. and Ikushima, K.: Seasonal changes in the distribution of dicarboxylic acids in the urban atmosphere, Environ. Sci. Technol., 27, 2227-2235, 1993.

Kleindienst, T. E., Smith, D. F., Li, W., Edney, E. O., Driscoll, D. J., Speer, R. E., and Weathers, W. S.: Secondary organic aerosol formation from the oxidation of aromatic hydrocarbons in the presence of dry submicron ammonium sulfate aerosol, Atmos. Environ., 33, 3669-3681, 1999.

Kreidenweis, S. M., Koehler, K., DeMott, P. J., Prenni, A. J., Carrico, C., and Ervens, B.: Water activity and activation diameters from hygroscopicity data - Part I: Theory and application to inorganic salts, Atmos. Chem. Phys., 5, 1357-1370, https://doi.org/10.5194/acp-5-1357-2005, 2005.

Lang-Yona, N., Abo-Riziq, A., Erlick, C., Segre, E., Trainic, M., and Rudich, Y.: Interaction of internally mixed aerosols with light, Phys. Chem. Chem. Phys., 12, 21-31, 2010.

Lei, T., Zuend, A., Wang, W. G., Zhang, Y. H., and Ge, M. F.: Hygroscopicity of organic compounds from biomass burning and their influence on the water uptake of mixed organic ammonium sulfate aerosols, Atmos. Chem. Phys., 14, 11165-11183, https://doi.org/10.5194/acp-14-11165-2014, 2014.

Lei, T., Zuend, A., Cheng, Y., Su, H., Wang, W., and Ge, M.: Hygroscopicity of organic surrogate compounds from biomass burning and their effect on the efflorescence of ammonium sulfate in mixed aerosol particles, Atmos. Chem. Phys., 18, 1045-1064, https://doi.org/10.5194/acp-18-1045-2018, 2018.

Lesins, G., Chylek, P., and Lohmann, U.: A study of internal and external mixing scenarios and its effect on aerosol optical properties and direct radiative forcing, J. Geophys. Res., 107, https://doi.org/10.1029/2001JD000973, 2002.

Liu, Q., Jing, B., Peng, C., Tong, S., Wang, W., and Ge, M.: Hygroscopicity of internally mixed multi-component aerosol particles of atmospheric relevance, Atmos. Environ., 125, 69-77, 2016. 
Liu, X., Zhang, Y., Cheng, Y., Hu, M., and Han, T.: Aerosol hygroscopicity and its impact on atmospheric visibility and radiative forcing in Guangzhou during the 2006 PRIDE-PRD campaign, Atmos. Environ., 60, 59-67, 2012.

Liu, X., Gu, J., Li, Y., Cheng, Y., Qu, Y., Han, T., Wang, J., Tian, H., Chen, J., and Zhang, Y.: Increase of aerosol scattering by hygroscopic growth: Observation, modeling, and implications on visibility, Atmos. Res., 132, 91-101, 2013.

Martin, A. C., Cornwell, G. C., Atwood, S. A., Moore, K. A., Rothfuss, N. E., Taylor, H., DeMott, P. J., Kreidenweis, S. M., Petters, M. D., and Prather, K. A.: Transport of pollution to a remote coastal site during gap flow from California's interior: impacts on aerosol composition, clouds, and radiative balance, Atmos. Chem. Phys., 17, 1491-1509, https://doi.org/10.5194/acp17-1491-2017, 2017.

Maskey, S., Chong, K. Y., Kim, G., Kim, J.-S., Ali, A., and Park, $\mathrm{K}$.: Effect of mixing structure on the hygroscopic behavior of ultrafine ammonium sulfate particles mixed with succinic acid and levoglucosan, Particuology, 13, 27-34, 2014.

Miñambres, L., Sánchez, M. N., Castaño, F., and Basterretxea, F. J.: Hygroscopic Properties of Internally Mixed Particles of Ammonium Sulfate and Succinic Acid Studied by Infrared Spectroscopy, J. Phys. Chem. A, 114, 6124-6130, 2010.

Mu, L., Yuan, Q., Tian, C., Wei, C., Zhang, K., Liu, J., Pianetta, P., Doeff, M. M., Liu, Y., and Lin, F.: Propagation topography of redox phase transformations in heterogeneous layered oxide cathode materials, Nat. Commun., 9, 2810, https://doi.org/10.1038/s41467-018-05172-x, 2018.

Pagels, J., Khalizov, A. F., McMurry, P. H., and Zhang, R. Y.: Processing of Soot by Controlled Sulphuric Acid and Water Condensation - Mass and Mobility Relationship, Aerosol Sci. Tech., 43, 629-640, 2009.

Peng, C., Chan, M. N., and Chan, C. K.: The Hygroscopic Properties of Dicarboxylic and Multifunctional Acids: Measurements and UNIFAC Predictions, Environ. Sci. Technol., 35, 44954501, 2001.

Qiu, C. and Zhang, R.: Multiphase chemistry of atmospheric amines, Phys. Chem. Chem. Phys., 15, 5738-5752, 2013.

Reutter, P., Su, H., Trentmann, J., Simmel, M., Rose, D., Gunthe, S. S., Wernli, H., Andreae, M. O., and Pöschl, U.: Aerosol- and updraft-limited regimes of cloud droplet formation: influence of particle number, size and hygroscopicity on the activation of cloud condensation nuclei (CCN), Atmos. Chem. Phys., 9, 70677080, https://doi.org/10.5194/acp-9-7067-2009, 2009.

Rogge, W. F., Mazurek, M. A., Hildemann, L. M., Cass, G. R., and Simoneit, B. R. T.: Quantification of urban organic aerosols at a molecular-level - identification, abundance and seasonalvariation, Atmos. Environ., 27, 1309-1330, 1993.

Rose, D., Gunthe, S. S., Su, H., Garland, R. M., Yang, H., Berghof, M., Cheng, Y. F., Wehner, B., Achtert, P., Nowak, A., Wiedensohler, A., Takegawa, N., Kondo, Y., Hu, M., Zhang, Y., Andreae, M. O., and Pöschl, U.: Cloud condensation nuclei in polluted air and biomass burning smoke near the megacity Guangzhou, China - Part 2: Size-resolved aerosol chemical composition, diurnal cycles, and externally mixed weakly CCN-active soot particles, Atmos. Chem. Phys., 11, 2817-2836, https://doi.org/10.5194/acp-11-2817-2011, 2011.
Rudich, Y.: Laboratory Perspectives on the Chemical Transformations of Organic Matter in Atmospheric Particles, Chem. Rev., 103, 5097-5124, 2003.

Saxena, P., Hildemann, L. M., McMurry, P. H., and Seinfeld, J. H.: Organics alter hygroscopic behavior of atmospheric particles, J. Geophys. Res.-Atmos., 100, 18755-18770, 1995.

Schauer, J. J. and Cass, G. R.: Source Apportionment of Wintertime Gas-Phase and Particle-Phase Air Pollutants Using Organic Compounds as Tracers, Environ. Sci. Technol., 34, 1821-1832, 2000.

Schauer, J. J., Rogge, W. F., Hildemann, L. M., Mazurek, M. A., Cass, G. R., and Simoneit, B. R. T.: Source apportionment of airborne particulate matter using organic compounds as tracers, Atmos. Environ., 30, 3837-3855, 1996.

Schauer, J. J., Fraser, M. P., Cass, G. R., and Simoneit, B. R. T.: Source Reconciliation of Atmospheric Gas-Phase and ParticlePhase Pollutants during a Severe Photochemical Smog Episode, Environ. Sci. Technol., 36, 3806-3814, 2002.

Schwarz, J. P., Gao, R. S., Fahey, D. W., Thomson, D. S., Watts, L. A., Wilson, J. C., Reeves, J. M., Darbeheshti, M., Baumgardner, D. G., Kok, G. L., Chung, S. H., Schulz, M., Hendricks, J., Lauer, A., Kärcher, B., Slowik, J. G., Rosenlof, K. H., Thompson, T. L., Langford, A. O., Loewenstein, M., and Aikin, K. C.: Single-particle measurements of midlatitude black carbon and light-scattering aerosols from the boundary layer to the lower stratosphere, J. Geophys. Res., 111, D16207, https://doi.org/10.1029/2006JD007076, 2006.

Shi, Y. J., Ge, M. F., and Wang, W. G.: Hygroscopicity of internally mixed aerosol particles containing benzoic acid and inorganic salts, Atmos. Environ., 60, 9-17, 2012.

Shiraiwa, M., Zuend, A., Bertram, A. K., and Seinfeld, J. H.: Gasparticle partitioning of atmospheric aerosols: interplay of physical state, non-ideal mixing and morphology, Phys. Chem. Chem. Phys., 15, 11441-11453, 2013.

Sjogren, S., Gysel, M., Weingartner, E., Baltensperger, U., Cubison, M. J., Coe, H., Zardini, A. A., Marcolli, C., Krieger, U. K., and Peter, T.: Hygroscopic growth and water uptake kinetics of twophase aerosol particles consisting of ammonium sulfate, adipic and humic acid mixtures, J. Aerosol Sci., 38, 157-171, 2007.

Song, M., Marcolli, C., Krieger, U. K., Zuend, A., and Peter, T.: Liquid-liquid phase separation and morphology of internally mixed dicarboxylic acids/ammonium sulfate/water particles, Atmos. Chem. Phys., 12, 2691-2712, https://doi.org/10.5194/acp12-2691-2012, 2012a.

Song, M., Marcolli, C., Krieger, U. K., Zuend, A., and Peter, T.: Liquid-liquid phase separation in aerosol particles: dependence on O:C, organic functionalities, and compositional complexity, Geophys. Res. Lett., 39, L19801, https://doi.org/10.1029/2012GL052807, 2012b.

Song, M., Ham, S., Andrews, R. J., You, Y., and Bertram, A. K.: Liquid-liquid phase separation in organic particles containing one and two organic species: importance of the average O:C, Atmos. Chem. Phys., 18, 12075-12084, https://doi.org/10.5194/acp-18-12075-2018, 2018.

Spindler, C., Riziq, A. A., and Rudich, Y.: Retrieval of Aerosol Complex Refractive Index by Combining Cavity Ring Down Aerosol Spectrometer Measurements with Full Size Distribution Information, Aerosol Sci. Tech., 41, 1011-1017, 2007. 
Stock, M., Cheng, Y. F., Birmili, W., Massling, A., Wehner, B., Müller, T., Leinert, S., Kalivitis, N., Mihalopoulos, N., and Wiedensohler, A.: Hygroscopic properties of atmospheric aerosol particles over the Eastern Mediterranean: implications for regional direct radiative forcing under clean and polluted conditions, Atmos. Chem. Phys., 11, 4251-4271, https://doi.org/10.5194/acp-11-4251-2011, 2011.

Su, H., Rose, D., Cheng, Y. F., Gunthe, S. S., Massling, A., Stock, M., Wiedensohler, A., Andreae, M. O., and Pöschl, U.: Hygroscopicity distribution concept for measurement data analysis and modeling of aerosol particle mixing state with regard to hygroscopic growth and CCN activation, Atmos. Chem. Phys., 10, 7489-7503, https://doi.org/10.5194/acp-10-7489-2010, 2010.

Tang, I. N. and Munkelwitz, H. R.: Water activities, densities, and refractive indices of aqueous sulfates and sodium nitrate droplets of atmospheric importance, J. Geophys. Res.-Atmos., 99, 1880118808, 1994.

Tie, X., Huang, R.-J., Cao, J., Zhang, Q., Cheng, Y., Su, H., Chang, D., Pöschl, U., Hoffmann, T., Dusek, U., Li, G., Worsnop, D. R., and O'Dowd, C. D.: Severe Pollution in China Amplified by Atmospheric Moisture, Sci Rep., 7, 15760, https://doi.org/10.1038/s41598-017-15909-1, 2017.

Wang, G., Kawamura, K., Xie, M., Hu, S., Li, J., Zhou, B., Cao, J., and An, Z.: Selected water-soluble organic compounds found in size-resolved aerosols collected from urban, mountain and marine atmospheres over East Asia, Tellus B, 63, 371-381, 2011.

Xue, H., Khalizov, A. F., Wang, L., Zheng, J., and Zhang, R.: Effects of dicarboxylic acid coating on the optical properties of soot, Phys. Chem. Chem. Phys., 11, 7869-7875, 2009.

You, Y., Smith, M. L., Song, M., Martin, S. T., and Bertram, A. K.: Liquid-liquid phase separation in atmospherically relevant particles consisting of organic species and inorganic salts, Int. Rev. Phys. Chem., 33, 43-77, 2014.

Zamora, I. R., Tabazadeh, A., Golden, D. M., and Jacobson, M. Z.: Hygroscopic growth of common organic aerosol solutes, including humic substances, as derived from water activity measurements, J. Geophys. Res.-Atmos., 116, https://doi.org/10.1029/2011jd016067, 2011.

Zawadowicz, M. A., Proud, S. R., Seppalainen, S. S., and Cziczo, D. J.: Hygroscopic and phase separation properties of ammonium sulfate/organics/water ternary solutions, Atmos. Chem. Phys., 15, 8975-8986, https://doi.org/10.5194/acp-158975-2015, 2015.
Zelenyuk, A., Cai, Y., and Imre, D.: From Agglomerates of Spheres to Irregularly Shaped Particles: Determination of Dynamic Shape Factors from Measurements of Mobility and Vacuum Aerodynamic Diameters, Aerosol Sci. Tech., 40, 197-217, 2006.

Zhang, Q., Canagaratna, M. R., Jayne, J. T., Worsnop, D. R., and Jimenez, J.-L.: Time- and size-resolved chemical composition of submicron particles in Pittsburgh: Implications for aerosol sources and processes, J. Geophys. Res., 110, D07S09, https://doi.org/10.1029/2004JD004649, 2005.

Zhang, R., Khalizov, A. F., Pagels, J., Zhang, D., Xue, H., and McMurry, P. H.: Variability in morphology, hygroscopicity, and optical properties of soot aerosols during atmospheric processing, P. Natl. Acad. Sci. USA, 105, 10291-10296, 2008.

Zhang, Y.-L., Kawamura, K., Watanabe, T., Hatakeyama, S., Takami, A., and Wang, W.: New directions: Need for better understanding of source and formation process of phthalic acid in aerosols as inferred from aircraft observations over China, Atmos. Environ., 140, 147-149, 2016.

Zhou, Q., Pang, S.-F., Wang, Y., Ma, J.-B., and Zhang, Y.-H.: Confocal Raman Studies of the Evolution of the Physical State of Mixed Phthalic Acid/Ammonium Sulfate Aerosol Droplets and the Effect of Substrates, J. Phys. Chem. B, 118, 6198-6205, 2014.

Zuend, A. and Seinfeld, J. H.: A practical method for the calculation of liquid-liquid equilibria in multicomponent organic-waterelectrolyte systems using physicochemical constraints, Fluid Phase Equilibria, 337, 201-213, 2013.

Zuend, A., Marcolli, C., Luo, B. P., and Peter, T.: A thermodynamic model of mixed organic-inorganic aerosols to predict activity coefficients, Atmos. Chem. Phys., 8, 4559-4593, https://doi.org/10.5194/acp-8-4559-2008, 2008.

Zuend, A., Marcolli, C., Booth, A. M., Lienhard, D. M., Soonsin, V., Krieger, U. K., Topping, D. O., McFiggans, G., Peter, T., and Seinfeld, J. H.: New and extended parameterization of the thermodynamic model AIOMFAC: calculation of activity coefficients for organic-inorganic mixtures containing carboxyl, hydroxyl, carbonyl, ether, ester, alkenyl, alkyl, and aromatic functional groups, Atmos. Chem. Phys., 11, 9155-9206, https://doi.org/10.5194/acp-11-9155-2011, 2011. 